\title{
Vertebral artery variations revised: origin, course, branches and embryonic development
}

\author{
E.-P. Magklara, E.-T. Pantelia, E. Solia, E. Panagouli®, M. Piagkou, A. Mazarakis, \\ P. Skandalakis, T. Troupis, D. Filippou \\ Anatomy Department, Medical School, National and Kapodistrian University of Athens, Greece
}

[Received: 29 November 2019; Accepted: 27 January 2020]

\begin{abstract}
Background: The vertebral artery originates from the subclavian artery and is divided into four segments. The aim of this study is to investigate the anatomical variations in the course and branches of the vertebral artery.

Materials and methods: A research was performed via PubMed database, using the terms: "variations of vertebral artery AND cadaveric study", "variations of vertebral artery AND cadavers" and "anomalies of vertebral artery AND cadavers".

Results: A total of 24 articles met the inclusion criteria, 13 of them referring to variations of the origin of the vertebral artery, 9 to variations of the course and 3 to variations of its branches. On a total sample of 1192 cadavers of different populations, origin of the left vertebral artery directly from the aortic arch was observed at $6.7 \%$. In addition, among 311 cadavers, $17.4 \%$ were found with partially or fully ossified foramen of the atlas for the passage of the vertebral artery, while the bibliographic review also showed variants at the exit site of the artery from the transverse foramen of the axis.

Conclusions: Despite the fact that variations of both the course and the branches of vertebral artery are in most cases asymptomatic, good knowledge of anatomy and its variants is of particular importance for the prevention of vascular complications during surgical and radiological procedures in the cervix area. (Folia Morphol 2021; 80, 1: 1-12)
\end{abstract}

Key words: subclavian artery, brachiocephalic trunk, aortic arch, posterior inferior cerebellar artery

\section{INTRODUCTION}

According to classical anatomical textbooks, the vertebral artery (VA) is divided into four segments [1]. In the first segment, the artery courses dorsally after originating from the subclavian artery until it enters the foramen of the $\mathrm{C} 6$. The second segment lies within the transverse foramina of $\mathrm{C} 6$ to $\mathrm{C} 2$. The third portion is the distal extracranial segment that is short and tortuous. The artery passes through the transverse foramen (TF) of the atlas and then curves backwards and medially behind the lateral mass of the atlas. It then makes a sharp turn to pierce the dura mater, thereby entering the cranium through the foramen magnum (Fig. 1). The fourth segment is entirely intracranial and terminates when the vertebral arteries join at the lower pontine border to form the basilar artery [10, 27]. The VA typically gives off spinal, muscular, meningeal branches, the anterior spinal artery, ramus choroideus ventriculi quarti, medial and lateral medullary branches and the terminal branch, the posterior inferior cerebellar artery (PICA) [62].

Anatomical variations of the VAs concerning their site of origin, course and branching pattern are 


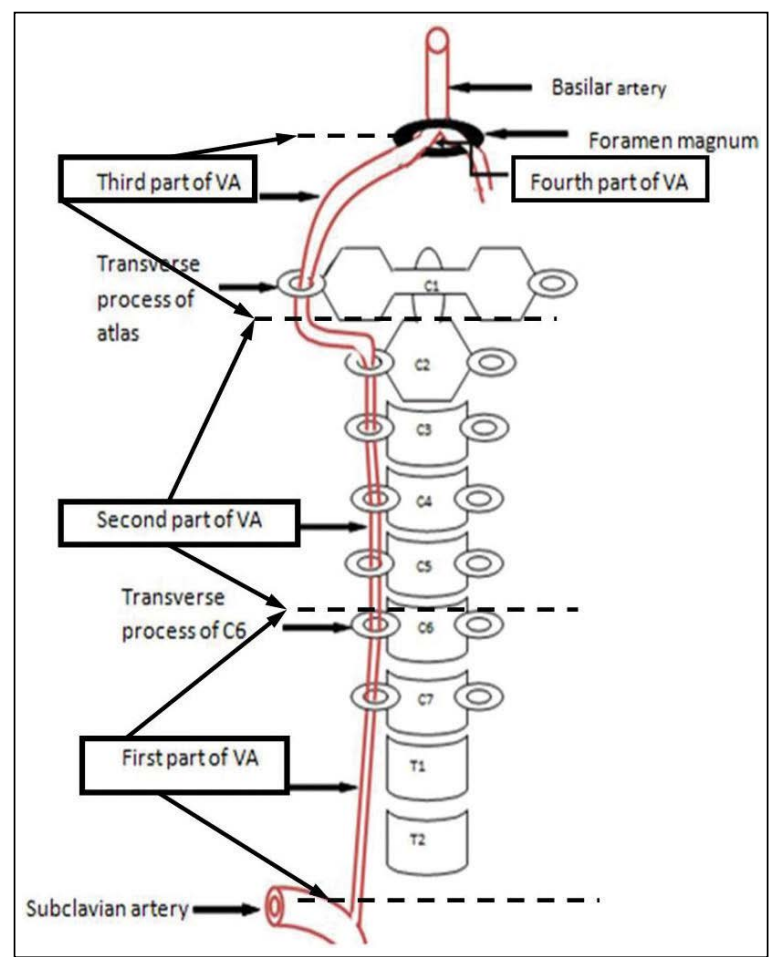

Figure 1. Origin and course of vertebral artery (VA). First part: from the origin of the vertebral artery until it enters the foramen of the C6. Second part: between transverse foramina of $\mathrm{C} 6$ to $\mathrm{C} 2$. Third part: from the transverse foramen until the foramen magnum. Fourth part: entirely intracranial.

not common and present particular clinical interest. Our study has been designed to take into account the reports in the literature so far, in order to investigate the different types of anatomical variations of the VAs and the corresponding incidences.

\section{MATERIALS AND METHODS}

An extensive literature search was conducted using the electronic database PubMed for relevant published articles. The search terms were; "variations of vertebral artery AND cadaveric study", "variations of vertebral artery AND cadavers" and "anomalies of vertebral artery AND cadavers". Only cadaveric studies in adults and in English language were included in this study. Computed tomography-scans and angiographic studies were excluded. Additional search filters such as article types, text availability, publication date and species were not applied. Collected data were categorised in tables according to the type of variation. The resulting citations were exported and the articles were screened independently. The references of identified publications and articles were also examined.

\section{RESULTS}

Eventually a total of 24 papers met inclusion criteria, 13 of them referred to variations of the origin of the VA, 9 to variations of the artery's course and 3 in variations of its branches. It should be noticed that among the 25 papers, one (Lang and Kessler 1991 [27]) referred both to the course and the branches of the artery, so it was counted twice. The articles ranged in date from 1983 to 2019 and included cadaveric studies in different populations.

The 13 studies concerning the VA's variable origin corresponded to a total number of 1192 cadavers. The results are presented in Table 1 and Figure 2 . An atypical VA origin was detected in $7.0 \%$ (83 out of 1192 cadavers) of the specimens. A direct origin of the left vertebral artery (LVA) from the aortic arch was observed in $6.7 \%$ of cases (80 out of 1192 cadavers). The right vertebral artery (RVA) presented less commonly an aberrant origin (3 cadavers out of $1192,0.25 \%$ ). These variations concerned RVA origin from the right common carotid artery (RCCA), from the brachiocephalic trunk (BCT) and double RVA - the one emerging from the aortic arch (AA) and the other from the right subclavian artery (RSCA).

The vertebral level of origin of the RVA and LVA was assessed only in 14 cadavers ( 1 study, Table 1). The prevalent level of origin of the LVA was between the $7^{\text {th }}$ cervical vertebra and the $1^{\text {st }}$ thoracic vertebra, while there were also 4 cases emerging between the $1^{\text {st }}$ and $2^{\text {nd }}$ thoracic vertebra. The RVA arose between the $7^{\text {th }}$ cervical vertebra and the $1^{\text {st }}$ thoracic vertebra in 5 cases and between the $1^{\text {st }}$ and $2^{\text {nd }}$ thoracic vertebra in 4 cases.

Concerning the course of the VA, 189 (30.1\%) variations were found among 628 cadavers (Table 2 , a total of 9 studies). Most of them were observed on second and third segment of the VA. Studies where the VA presented anomalous origin were excluded.

The variations concerning the branching pattern of the VA are represented in Table 3 (3 studies).

\section{DISCUSSION}

According to our review of the literature, the direct origin of the LVA from the AA was observed in $6.7 \%$ of the cases. In most occasions the LVA emerged between the left common carotid artery (LCCA) and the left subclavian artery (LSCA). A unique case of a LVA origin between the BCT and the LSCA was reported, while in this specimen the LCCA orig- 
Table 1. Total number of studies and specimens presenting variations in the origin of the vertebral artery (VA).

\begin{tabular}{|c|c|c|c|c|}
\hline Researchers & Year & Specimens & Variations & Per cent \\
\hline Vorster et al. [56] & 1998 & 60 South African cadavers & LVA origin from the $A A(3)$ & $5 \%$ \\
\hline Gluncic et al. [19] & 1999 & 1 cadaver & $\begin{array}{l}\text { LVA origin from the AA in a common trunk with LSCA } \\
\text { RVA origin from the RCCA }\end{array}$ & \\
\hline Yamaki et al. [61] & 2006 & 515 Japanese cadavers & $\begin{array}{l}\text { RVA origin from the bifurcation of the BCT (1) } \\
\text { LVA origin from the } A A(30)\end{array}$ & $\begin{array}{l}0.2 \% \\
5.8 \%\end{array}$ \\
\hline Ikegami et al. [24] & 2007 & 25 cadavers & LVA origin from the AA (1) & $4 \%$ \\
\hline \multirow[t]{12}{*}{ Shin et al. [47] } & 2008 & 25 Korean cadavers & LVA origin from the $A A(2)$ & $8 \%$ \\
\hline & & & LVA — level of origin: & \\
\hline & & & $\mathrm{C} 7 / \mathrm{T} 1: 5$ & $35.7 \%$ \\
\hline & & & $\mathrm{T} 1 / \mathrm{T} 2: 4$ & $28.5 \%$ \\
\hline & & & $\mathrm{T} 2: 1$ & $7.1 \%$ \\
\hline & & & T2/T3:1 & $7.1 \%$ \\
\hline & & & $\mathrm{T} 1: 3$ & $21.4 \%$ \\
\hline & & & RVA — level of origin: & \\
\hline & & & $\mathrm{C} 7 / \mathrm{T} 1: 6$ & $42.8 \%$ \\
\hline & & & $\mathrm{T} 1: 3$ & $21.4 \%$ \\
\hline & & & $\mathrm{T} 1 / \mathrm{T} 2: 4$ & $28.5 \%$ \\
\hline & & & C7:1 & $7.1 \%$ \\
\hline Patil et al. [41] & 2012 & 75 Indian cadavers & LVA origin from the $A A(6)$ & $8 \%$ \\
\hline Budhiraja et al. [8] & 2013 & 52 Indian cadavers & LVA origin from the $A A(9)$ & $17.3 \%$ \\
\hline Einstein et al. [16] & 2016 & 27 cadavers & LVA origin from the AA (4) & $14.8 \%$ \\
\hline Singh [49] & 2017 & 2 Indian cadavers & $\begin{array}{l}\text { LVA origin from the AA (1) } \\
\text { LVA origin from a common trunk with LSCA (1) }\end{array}$ & \\
\hline Motomura et al. [35] & 2018 & 1 cadaver & $\begin{array}{c}\text { Duplicated RVA with a proximal leg arising from the AA and } \\
\text { a distal one with typical origin from RSCA }\end{array}$ & \\
\hline O'Malley et al. [39] & 2018 & 24 Irish cadavers & LVA origin from the $A A(2)$ & $8.3 \%$ \\
\hline Li et al. [30] & 2018 & 119 cadavers & LVA origin from the AA (7) & $5.89 \%$ \\
\hline Woraputtaporn et al. [60] & 2018 & 266 Thai cadavers & LVA origin from the $A A(14)$ & $5.3 \%$ \\
\hline
\end{tabular}

AA — aortic arch; BCT — brachiocephalic trunk; LSCA — left subclavian artery; LVA — left vertebral artery; RCCA — right common carotid artery; RSCA — right subclavian artery; RVA - right vertebral artery

inated from a common trunk with the BCT. Additionally, in two cases the LVA derived from the AA from a common trunk together with the LSCA $[19,49]$.

In order to understand the majority of VA variations, a deep knowledge of embryological development of the AA and its branching pattern is required. During embryological development, as the heart and aorta move caudally, cervical intersegmental arteries appear from the AA [16]. The $1^{\text {st }}$ to $6^{\text {th }}$ dorsal intersegmental arteries are anastomosed lengthwise, with their inferior end connected to the $7^{\text {th }}$ dorsal intersegmental artery [61]. The first part of the LVA develops close to the origin of the dorsal branch of the $7^{\text {th }}$ cervical intersegmental artery and proximal to the postcostal anastomosis, while the second part is derived from longitudinal communications of the postcostal anastomosis. To enter into the foramen transversarium of $6^{\text {th }}$ cervical vertebra, the vessel takes a vertical posterior course [8].

Even though AA variations may be discovered in the very first days of life, the majority are only discovered after death or randomly on imaging methods, due to the absence of symptoms [39]. Even though the exact cause of such variations is unknown [39], a plethora of embryological explanations is contained in the literature. From the aspect of Patil et al. (2012) [41], variations in the branches of the AA might be a result of modified development of certain arteries of the AA during pregnancy. Furthermore, Patil et al. (2012) [41] suggested that a large absorption of embryonic tissue of the LSCA between the origin of the VA and the AA may cause a direct origin of the 


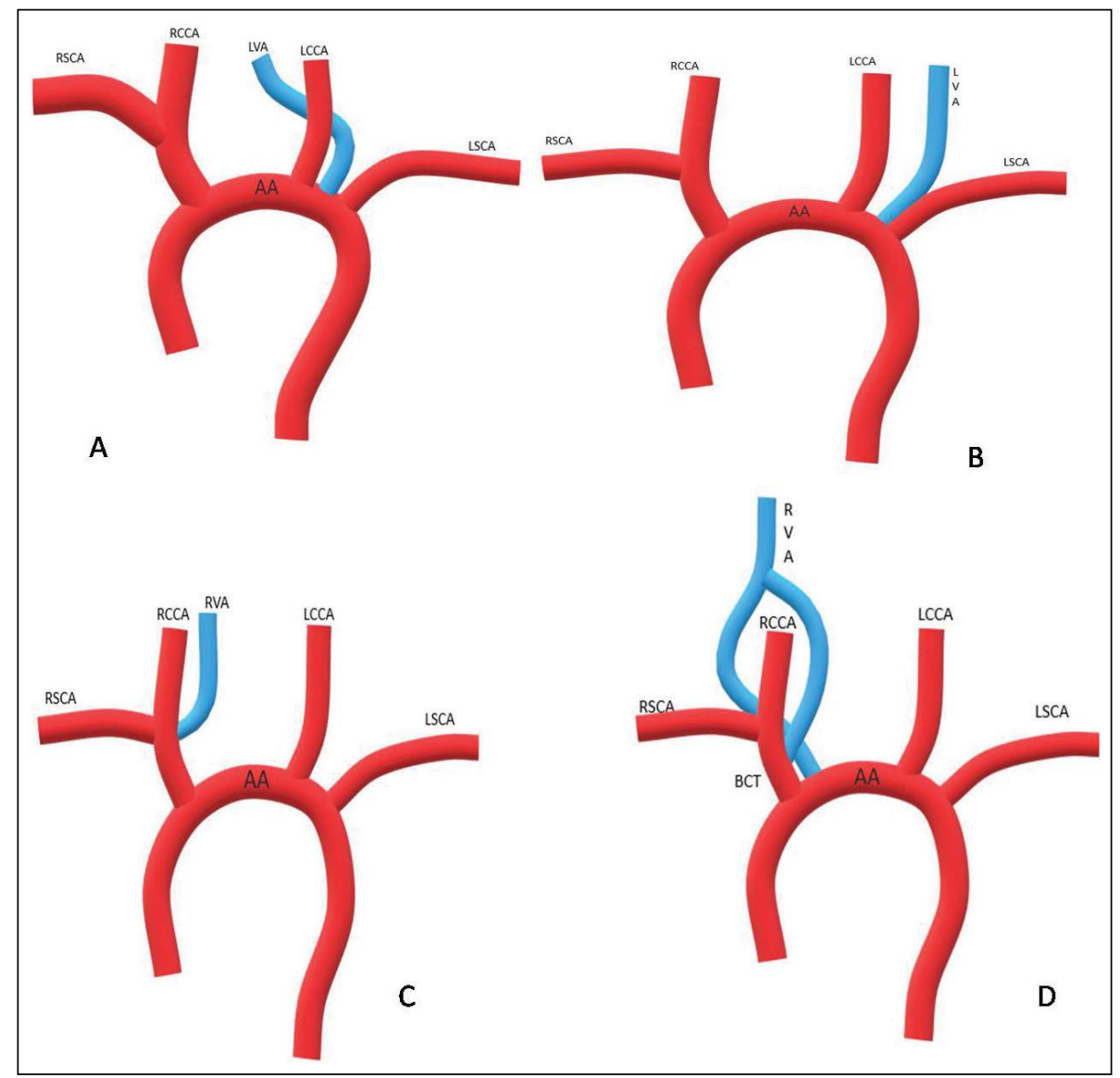

Figure 2. Variations of vertebral artery (VA) origin; A. Left vertebral artery (LVA) originated from aortic arch (AA); right vertebral artery (RVA) of typical origin; B. LVA originated from AA with a common trunk with left subclavian artery (LSCA), RVA of typical origin; C. RVA originated from brachiocephalic trunk (BCT), LVA of typical origin; D. Duplicated RVA originated from BCT and AA, LVA of typical origin; LCCA — left common carotid artery; RCCA — right common carotid artery; RSCA — right subclavian artery.

LVA from the AA, between the origins of the LSCA and LCCA. Adachi (1928) [2] classified this pattern as type III. Budhiraja et al. (2013) [8] assumed that the first part of VA could be the preserved left $6^{\text {th }}$ segmental artery, or there might be a large absorption of the embryonic tissue of LSCA, between the origin of the $A A$ to the origin of $V A$, causing direct origin of the LVA from the AA. The $6^{\text {th }}$ cervical intersegmental artery customarily vanishes, but Einstein et al. (2016) [17] supposed that it might have maintained, permitting blood flow from the arch of aorta. The cause of origin of the LVA from the AA might be the decreased blood flow through the normal origin of the LVA which is the dorsal division of the $7^{\text {th }}$ cervical intersegmental artery. According to Yamaki et al. (2006) [61], this anomalous origin of the LVA could be explicated by the fact that the LVA is probably formed through the conjunction of the $4^{\text {th }}$ branchial artery with the superior wall of the arch of aorta. Additionally, growth factors such as transforming growth factor beta and vascular endothelial growth factor may play a significant role in the variable patterns of the AA and its branches [5]. Bhimabhai et al. (2014) [6] suggest that $A A$ variations may be a result of deficient branching of the aortic sac into the right and left limbs during embryonic growth, while Momma et al. (1999) [34] propose that there is a relationship between $A A$ variants and a loss of chromosome 22q11. Moreover, other congenital conditions such as Klippel-Feil syndrome or Down syndrome and rheumatoid arthritis have been associated with VA variations [57].

Concerning the clinical implications of the variations of the LVA origin, Budhiraja et al. (2013) [8] noticed that atherosclerosis often affects the prevertebral part of the LVA deriving from the AA. Einstein et al. (2016) [17] stated that an abnormal origin of LVA doesn't have any impact on blood flow, but it might perplex surgical and endovascular 
Table 2. Variations in the course of the vertebral artery (VA)

\begin{tabular}{|c|c|c|c|c|}
\hline Researchers & Year & Specimens & Variations & Per cent \\
\hline \multirow{3}{*}{$\begin{array}{l}\text { De Oliveira and } \\
\text { Rhoton [15] }\end{array}$} & \multirow[t]{3}{*}{1985} & \multirow[t]{3}{*}{25 cadaveric heads } & In the suboccipital region: & \\
\hline & & & - VA was partially, but incompletely, surrounded by bone (6) & $24 \%$ \\
\hline & & & - Bony ring that completely surrounds the VA (7) & $28 \%$ \\
\hline \multirow{8}{*}{$\begin{array}{l}\text { Lang and Kessler } \\
\text { [27] }\end{array}$} & \multirow[t]{8}{*}{1991} & \multirow{8}{*}{$\begin{array}{l}65 \text { head and neck } \\
\text { halves }\end{array}$} & V3 segment & \\
\hline & & & Loop formation at the exit from the transverse foramen of $\mathrm{C} 2$ : & \\
\hline & & & - Sideward loop caudally and dorsally (Type II) (9) & $14 \%$ \\
\hline & & & - Clear loops in the dorsal direction (Type III) (7) & $10.8 \%$ \\
\hline & & & - Slant course from the transverse foramen of C2 sideward and upward (Type IV) (7) & $10.8 \%$ \\
\hline & & & Variations of $\mathrm{V} 2$ segment: & \\
\hline & & & - In the space between C6 and C2 it meanders slightly (5) & $7.7 \%$ \\
\hline & & & - Clear loops (2) & $3.1 \%$ \\
\hline \multirow[t]{2}{*}{ Cacciola et al. [9] } & \multirow[t]{2}{*}{2004} & \multirow[t]{2}{*}{40 cadavers } & $\begin{array}{l}\text { - Atlas with symmetrical complete bilateral dorsal osseous bridges, passage of VA } \\
\text { through the tunnel formed by the dorsal and lateral bridges (1) }\end{array}$ & $2.5 \%$ \\
\hline & & & $\begin{array}{l}\text { - VA passage from lateral to medial under the oblique inferior boarder of the partially } \\
\text { ossified atlanto-occipital membrane (2) }\end{array}$ & $5 \%$ \\
\hline \multirow{3}{*}{$\begin{array}{l}\text { Senoglu et al. } \\
\text { [46] }\end{array}$} & \multirow[t]{3}{*}{2006} & \multirow{3}{*}{$\begin{array}{l}166 \text { dry C1 } \\
\text { specimens }\end{array}$} & Variations of V3 segment: & \\
\hline & & & - Bilateral osseous bridges forming a canal for VA (8) & $4.8 \%$ \\
\hline & & & - Unilateral osseous bridges forming a canal for VA (10) & $6 \%$ \\
\hline Tubbs et al. [53] & 2006-2007 & 20 cadavers & Bilateral LAO ligament, dorsally in contact with the VA (20) & $100 \%$ \\
\hline \multirow[t]{3}{*}{ Civelek et al. [13] } & \multirow[t]{3}{*}{2007} & \multirow[t]{3}{*}{30 cadavers } & Variations at the VA entrance point in the transverse canal (V2 segment): & \\
\hline & & & - Entrance into the transverse foramen of C7 (2) & $7 \%$ \\
\hline & & & - Entrance into the transverse foramen of $\mathrm{C} 4$ (1) & $3 \%$ \\
\hline \multirow[t]{2}{*}{$\begin{array}{l}\text { Muralimohan et } \\
\text { al. [36] }\end{array}$} & \multirow[t]{2}{*}{2009} & \multirow[t]{2}{*}{21 Indian cadavers } & $\begin{array}{l}\text { - On the right side completely ossified bridging fibrous tissue forming a bony } \\
\text { tunnel for VA (1) }\end{array}$ & $4.7 \%$ \\
\hline & & & - On the left side partially ossified bridging fibrous tissue forming a bony tunnel for VA (1) & $4.7 \%$ \\
\hline \multirow[t]{11}{*}{ Ulm et al. [54] } & \multirow[t]{11}{*}{2011} & \multirow[t]{5}{*}{30 cadavers } & Variations of $\mathrm{V} 3$ segment: & \\
\hline & & & Exit of VA from the C2 transverse foramen: & \\
\hline & & & - $90^{\circ}$ bend (15) & $50 \%$ \\
\hline & & & $\cdot<90^{\circ}$ angle (11) & $37.5 \%$ \\
\hline & & & - > $90^{\circ}$ angle (4) & $12.5 \%$ \\
\hline & & \multirow[t]{5}{*}{25 cadavers } & Proximal loop formation from its exit from the C2 foramen: & \\
\hline & & & - Posteriorly (12) & $48 \%$ \\
\hline & & & - Directly laterally (5) & $20 \%$ \\
\hline & & & - Little or no loop present (straight line between C1-C2) (8) & $32 \%$ \\
\hline & & & - No space between the occipital bone and the horizontal segment (4) & $12 \%$ \\
\hline & & 34 cadavers & Dorsal course through a fully foramen-shaped arterial groove (5) & $14.7 \%$ \\
\hline \multirow{4}{*}{$\begin{array}{l}\text { Chanapa and } \\
\text { Mahakkanukrauh } \\
\text { [12] }\end{array}$} & \multirow[t]{4}{*}{2012} & \multirow[t]{4}{*}{181 cervical spines } & Entrance of the VA into the transverse foramen of: & \\
\hline & & & $\cdot$ C4 (4) & $1.1 \%$ \\
\hline & & & $\cdot$ C5 (16) & $4.4 \%$ \\
\hline & & & - C7 (20) & $5.5 \%$ \\
\hline
\end{tabular}

processes of AA. The impairment or disengagement of the abnormal vessel might also affect cerebral function. According to the literature, there seems to be a greater hazard during surgical processes of important interruption of cerebral blood flow, if an anomalous VA exists [16]. Thus, a thorough knowl- edge of variations in the branching pattern of the $A A$ is essential, especially when patients have to experience aortic instrumentation, vessel angiography, or surgery on neck and head [41]. Additionally, a comprehensive understanding of possible abnormal branches emerging from the $A A$ is also vital in the 
Table 3. Variations in the branches of the vertebral artery (VA)

\begin{tabular}{|c|c|c|c|c|c|c|c|}
\hline Researchers & Year & Total specimens & \multicolumn{3}{|l|}{ Variations } & \multicolumn{2}{|c|}{ Per cent } \\
\hline Lang and Kessler [27] & 1991 & 65 head and neck halves & 3 specimens origin $\mathrm{fr}$ & extrad & gins & \multicolumn{2}{|c|}{$\sim 4 \%$} \\
\hline \multirow[t]{6}{*}{ Abd El-Bary et al. [1] } & \multirow[t]{6}{*}{1995} & \multirow[t]{6}{*}{14 cadavers } & \multicolumn{5}{|c|}{ Branches of the atlantic part of VA } \\
\hline & & & & Left & Right & Left & Right \\
\hline & & & Radiculomuscular & 14 & 14 & $100 \%$ & $100 \%$ \\
\hline & & & Muscular & 4 & 4 & $28.6 \%$ & $28.6 \%$ \\
\hline & & & Postmeningeal & 4 & 6 & $28.6 \%$ & $42 \%$ \\
\hline & & & Postspinal & 4 & 5 & $28.6 \%$ & $35.7 \%$ \\
\hline Wang et al. [58] & 2019 & 1 cadaver & \multicolumn{5}{|c|}{ Extradurally bilateral PICA origin between $\mathrm{C} 1$ and $\mathrm{C} 2$, and a right double-origin PICA } \\
\hline
\end{tabular}

PICA — posterior inferior cerebellar artery

identification of cranial aneurysms. Moreover, there have been reports that anomalies in the branching pattern of the AA could lead to cerebral anomalies by modifying the pattern of flow in cerebral vessels. Direct origin of LVA from AA seems to increase blood flow in LVA. This direct flow of blood from aorta to brain or absence of equilibrated flow of blood on right and left side at circle of Willis may probably be the cause of greater occurrence of cerebro-vascular diseases in such cases [44].

Our review of the literature retrieved only 1 case of a duplicated RVA (Table 1 [35]). Sim et al. (1976) [48] suggested that this variation may be the result of a remaining portion of the primitive dorsal aorta along with two intersegmental vessels conjoined to the true VA, while Kendi et al. (2009) [25] proposed that the miscarriage of regression of the $5^{\text {th }}$ or $6^{\text {th }}$ intersegmental arteries may lead to a further potential origin of the VA along with the normal $7^{\text {th }}$ segment. Duplicated RVA might be observed only in $1 \%$ of Japanese people and it is even rarer in Western Europe population [1]. It occurs mainly in the upper cervical position and is associated with other intracranial anomalies. When duplicated, there is either a main trunk which permeates the dura at the C1-C2 levels and a hypoplastic one or two trunks, one intradural and one extradural, of similar dimension. This probably leads to an acute haematoma below the inner layer of the dura and death, after tapping costal the cervical spine.

In respect to the variations of the RVA origin, our review retrieved a few cases of RVA emerging from the RCCA and the BCT as well as the duplication of the artery which was described above (total incidence of $0.25 \%$ ). Maiti et al. (2016) [31] mentioned that anomalous origin of the RVA is more frequent than that of the LVA. This result coincides with the findings of our review. The embryologic explanation is often difficult to understand. Although these findings may be asymptomatic in most cases, detailed information is required before any surgical/ endovascular intervention in order to avoid any inattentive injury and misconception of VA [8]. In general, abnormal origin of VA might cause cerebral disorder as it modifies haemodynamic of the brain [8].

Lazaridis et al. (2018) [29] presented in their study an interesting classification system concerning the variable point of origin of both VA. In most of the cases the left or right VA is described to emerge abnormally from different parts of the $A A$, while extra-aortic points of origin, such as the BCT and carotid arteries are included [29]. Nevertheless, the classification does not mention the point entrance and branching pattern.

Variations related to the entrance point and the course of the second segment in the transverse canal, were noticed in 2 studies and a total of 43 cadavers $(20 \%$, Table $2[12,53])$. The VA entered the TF of C6 in 168 out of 211 specimens (80\%). In 5 cadavers it entered in the TF of C4 $(2.3 \%)$, in 16 cadavers in the TF of $\mathrm{C} 5$ (7.6\%) and in 22 specimens the entrance point of VA was observed in the TF of C7 (10.4\%) [12, 31]. Chanapa and Mahakkanukrauh (2012) [12] reported the $47.5 \%$ of the observed variations were on the left side and the $52.5 \%$ were on the right side. The $57.5 \%$ of the cases which presented variations at the level of entry of the VA were men and the $42.5 \%$ were female [12]. Previous studies [7, 22, 31] reported that the VA entered typically at C6 with a range from $90 \%$ to $94.9 \%$, while an abnormal entrance at C3, C4, C5, and $C 7$ was observed with a range from $5.1 \%$ to $10 \%$. 
Chanapa and Mahakkanukrauh (2012) [12] reported that the entrance was found in $89 \%$ at the $\mathrm{C} 6$, which is compatible with the study of Civelek (2007) [13]. According to our review, the VA entered typically at C6 in $80 \%$ of the cases and the abnormal entrance occurred in $20 \%$ (C7, C5, and C4 with incidences $10.4 \%, 7.6 \%$, and $2.3 \%$, respectively). The unilateral entry of VA in the study of Chanapa and Mahakkanukrauh (2012) [12] was $13 \%$ similar to the study of Bruneau (2006) [7], which was $12.4 \%$. Ebraheim et al. (1996) [16] reported that serious VA compression, particularly when cervical spondylosis is present, may occur within the TF of C5 spine due to the small diameter of this foramen.

It should be pointed out that LVAs with abnormal origin from the AA tend to present variable and anomalous point of entrance. In the study of Woraputtaporn et al. (2018) [60] the 78.6\% of LVAs deriving from the AA entered the TF of $C 5$, with one entering that of the $\mathrm{C} 4$. On the right side, no deviations were observed at the origin pattern and the $99.2 \%$ of RVA assessed the C6 [60]. That was also the case in the study of Li et al. (2018) [30], where variations with a sinuous course and abnormal entry at the TF of $C 5$ were reported only in LVAs with atypical origin. According to Tardieu et al. (2017) [51], all cases of LVA with this type of origin ascended in a more medial course and presented higher point of origin, being more prompt to injuries.

Concerning the entrance of VA in the transverse canal, in $89 \%$ the artery ran nearly straight in this area, in $7.7 \%$ it meandered slightly and in $3.1 \%$ it formed clear loops [26]. In reference to the third segment of the VA, out of a total sample of 628 cadavers, variations were detected in 119 of them (19\%, Table 2). Ulm et al. (2010) [54] found that half of the VA specimens presented a $90^{\circ}$ bend at their exit point at the C2 TF, 37.5\% made a slightly more acute angle and $12.5 \%$ formed an obtuse bend inside the groove. In the same study, 25 dissections at the level of the third segment were examined, specifically at the proximal loop, which is tethered between the bony $\mathrm{C} 1$ and $\mathrm{C} 2$ foramina. The proximal loop projected posteriorly in $12(48 \%)$ cases and directly laterally in $5(20 \%)$ cases; in $8(32 \%)$ cases there was a small or no loop and the artery coursed in a straight line between $\mathrm{C} 1$ and $\mathrm{C} 2$. No case in which the proximal loop projected medially or anteriorly was observed. The superior surface of the horizontal segment is in close proximity to the lower lateral surface of the occipital bone. Ulm et al. (2010) [54] found no separation between the lower surface of the occiput and the superior surface of the third segment in $12 \%$ of cadaveric dissections (4/39).

Lang and Kessler (1991) [27] studied the course of the atlantoaxial part of the VA in 65 head and neck halves and presented 4 main types (I-IV) of loop formation in this region. According to their division, the type I which referred to the classical course of the artery was found in $42(64.6 \%)$ specimens. This course was discovered in $64.6 \%$ of the cases on the right and in $62.5 \%$ on the left. Type II included VAs which formed a loop sideward more or less caudally and slightly dorsally after their exit from the TF of the axis. This form occurred in $9(14 \%)$ specimens, more often on the left $(18.8 \%)$ than on the right $(9.1 \%)$. The cases where VA presented clear loops in the dorsal direction and then coursed upward to the TF of the axis belonged to the type III. This type was observed in $7(10.8 \%)$ specimens, more often on the left $(12.5 \%)$ than on the right $(9.1 \%)$. Finally, type IV was comprised of the arteries which coursed slantingly from the transverse foramen of the axis sideward and upward, with more or less clear curves of the vessel in the ventral direction before it approached the TF of the atlas. This type occurred in $10.8 \%$; in $15.2 \%$ the slanting course was to the right and in $6.3 \%$ to the left. Furthermore, they compared both sides in only 32 specimens ( 12 males, 4 females) and discovered the same type on each side in $56.3 \%$.

Probably the loop formation of the atlantoaxial part was firstly investigated by Krayenbühl and Yasargil (1957) [26]. These authors as well as Schwedt in 1978 [45] described different subdivisions: slight bendings, small curves, nearly or no loop formation and moderate looping and so on. Toldt and Hoschstetter (1979) [52] presented these bends in their illustrations. Francke et al. (1981) [18] subdivided the loops (concave downward and laterally and inside the TF of $\mathrm{C2}$ ) and pointed out that these bends seem to increase during aging. According to Muralimohan et al. (2009) [36], the incidence of VA variations in the atlantoaxial region is $2.3 \%$. Ulm et al (2010) [54] stated that this variant anatomy must be taken into consideration when placing either $\mathrm{C} 2$ pars screws or C1-2 transarticular screws, as both these techniques are likely to cause damage of this segment. Thus, detailed knowledge of the anatomy of this arterial segment is critical for the surgeon so that 
no accidental injury occurs. In addition, according to Heros (1986) [22], an intraoperative injury to the VA may result in unpredictable neurological deficits depending on contralateral VA flow due to excessive bleeding and disruption of cerebral blood flow.

As the artery exits the transverse foramen of $\mathrm{C} 1$, heading towards to the suboccipital region, it typically runs through the groove of the VA found in the posterior arch of $\mathrm{C} 1$. One of the most common variations observed in our review study was the presence of an osseous foramen on the posterior arch of the atlas, which is referred in the literature as Foramen Arcuale (FA) (or Ponticulus Posterior) [26]. This foramen, which is formed by the ossification of the atlanto-occipital membrane, transforms the groove of VA in an osseous tunnel inside of which the artery passes through to the suboccipital region. Among 252 cadavers [3, 26, 36, 46, 54] a total (33 out of $41,80.5 \%$ ) or partial (8 out of $41,19.5 \%$ ) ossification of the atlanto-occipital membrane was observed in $41(16.3 \%$ ) (Table 2). Corresponding findings were reported by Senoglu et al. (2006) [46] in 8 cadavers bilateral and in 10 unilateral (166 specimens), while no statistically significant difference between left and right side was reported.

The osseous bridge forming the canal for the VA variant was reported for the first time in the late $19^{\text {th }}$ century [32]. According to Manjunath (2001) [32], this variant anatomy was detected on $11.7 \%$ of $\mathrm{C} 1$ vertebrae observed in 60 southern Indians and was reported to occur in $1.8 \%$ to $29.2 \%$ of individuals in various geographic locations. Taitz and Nathan (1986) [50] investigated the existence of posterior and/or lateral bone bridges in $672 \mathrm{C} 1$ vertebrae. They found partial posterior bridges in 174 (25.9\%) and complete bridges in $53(7.9 \%)$ cases. Paraskevas et al. (2005) [40] examined 176 dried C1 vertebrae and found a canal for the VA in $10.2 \%$ and an incomplete canal in $24.4 \%$ of their specimens. This variant was observed less frequently in the specimens of Senoglu et al. (2006) [46] (bilaterally in $4.8 \%$, unilaterally in $6 \%$, and partially in 4.8\%). Afsharpour et al. (2016) [3] reported that the presence of arcuate foramina may compress the VA as it passes beneath the bony bridge. This compression could result in neurological conditions as vertebrobasilar arterial insufficiency (VBAI). Same symptoms may occur during surgical procedures near the atlas in patients with a FA. Mitchell (1998) [33] and Vanitha (2014) [55] concluded that hyper- extension of the head or manual pressure in this region during cervical manual manipulation is more likely to provoke VA compression, especially when FA is present, resulting in stenosis. Nevertheless, Haynes (2005) [20] didn't observe any incidence of VA stenosis using a Doppler examination. Cushing et al. (2001) [14] reported that the presence of FA could increase the risk of VA dissection especially with neck rotation. In a comprehensive study of 895 patients, Wight et al. (1999) [59] found out that complaints of neck pain (33\%) and cervicogenic headache $(22 \%)$ were significantly connected with the presence of FA. Pękala et al. (2017) [42] detected that the complete FA was reported to be predominant in North Americans (11.3\%) and Europeans $(11.2 \%)$, and less common among Asians (7.5\%). The complete FA was observed more frequently in males $(10.4 \%)$ than in females $(7.3 \%)$. On the opposite, an incomplete FA was more commonly observed in females (18.5\%) than in males $(16.7 \%)$. Additional to a complete FA, a contralateral FA was found in $53.1 \%$ of the cases. In our review study, the bilateral presence of FA was observed in $44.4 \%$ of cases (Table 2). Conclusively, the patient's sex and ethnicity should be taken into consideration by the surgeons while examining the presence of FA. Pre-screening clinical assessment of classic signs and symptoms of VBAl is also of great importance. Radiographic imaging is recommended for assessing the presence of partial or complete FA. In trauma cases, advanced imaging is strongly recommended. In order to minimise the risk of VA injuries from screw placement, attentive evaluation of dorsal-lateral arch thickness is a prerequisite, since FA seems to be a common anomaly. A thorough knowledge of the variants in this region and a detailed appreciation of regional anatomy of the FA are therefore imperative during surgical procedures in this area, as mentioned by Ahn et al. (2018) [4]. However, based on Afsharpour et al. (2016) [3] findings, the presence of such hard bridges over the VA may provide protection from compressive pressures. The same conclusion was reached by Muralimohan et al. (2009) [36] who assumed that although anatomical variations may potentially increase the rate of intraoperative complications, this osseous bridge constitutes an additional barrier which protects the artery, thus it reduces the risk of injury. This is also mentioned in the study of Senoglu et al. (2006) [46]. 
Tubbs et al. (2007) [53] have reported in their study that all 20 cadavers they had studied presented a lateral atlanto-occipital ligament (LAO) bilaterally, in contact with the VA posteriorly. They reported that this ligament was found to be a distinct band of connective tissue located lateral to the atlanto-occipital junction, separate from the joint capsule and the anterior atlanto-occipital membrane. The insertion of the LAO was observed onto the jugular process of the occipital bone in all specimens [53]. Although Tubbs et al. [53] reported that the presence of the LAO ligament was in close relation with the VA in all their specimens, this ligament is not frequently mentioned in literature and almost absent from all modern textbooks and atlases of anatomy. Some of the texts that have depicted this ligament include the antiquated editions of Gray's anatomy [43]. On the other hand, Hecker (1922) [21], in a landmark treatise on the atlanto-axial-occipital ligaments, didn't mention the LAO. The exclusion of this ligament may be linked to the difficulty to access this region. In case of accidents which might lead to the injury of this ligament, consequential damage in the VA may occur. Therefore, further research of the LAO must be taken into consideration, due to the proximity of this ligament to the VA.

According to Russo et al. (2011) [44], iatrogenic damage in the second segment of the VA is rare. However, the anomalous course of the VA may provoke serious complications during anterior cervical decompression surgery with consequential neurological damage or death. Thus, accurate preoperative planning is prerequisite for anterior cervical decompression [38]. Surgical approaches to the posterolateral craniovertebral junction require working in close proximity to the V3 segment. Therefore, Ulm et al. (2010) [54] concluded that an injury of this segment may occur during procedures of the craniovertebral junction, as well as while its exposure when treating tumours. They also mentioned that an injury of the VA may lead to serious complications such as VA occlusion, formation of an arteriovenous fistula, a pseudoaneurysm, or enormous bleeding that could result in stroke or even death $[38,54]$.

After the VA enters the suboccipital region, it gives off spinal and muscular branches, which supply the upper portion of the spinal cord and the suboccipital muscles, respectively. During its passage through the dura matter, meningeal branches are emerged. As it courses intercranial, it gives off its terminal branch, the PICA which is the largest branch of the VA and may be originated from the foramen magnum to the vertebrobasilar junction [1]. According to Lang and Kessler (1991) [25] the PICA emerged from the VA with extradural origins in 3 out of 63 head and neck halves (about 4\%), while double-origin PICA extradurally between the vertebrae $\mathrm{C} 1$ and $\mathrm{C} 2$ is observed in $1-4 \%$ of patients [58].

During surgical procedures of the VA, the branches of the VA in the axoatlantal and atlantal segments must be taken into consideration. Lang (1983) [28] was the first who analysed the extradural origins of PICA. It should be noticed that there are a plenty of variations concerning the distance from the lower rim of the TF of the atlas to the dura. Abd et al. (1995) [1] have noticed that the right and left VA often presents an asymmetry. A small VA is difficult to be observed with angiography and perhaps it terminates as PICA. Moreover, PICA termination is highly prevalent in cases of LVA origin from the AA [38]. In case it is ending in the basilar trunk it is termed "hypoplastic"; otherwise it is called "atretic" [38]. Additionally, there is a possibility of absence of this artery, so 4 congenital anastomotic arteries might exist: the trigeminal, otic, and hypoglossal which are intracranial and the proatlantal which is extracranial. All of them constitute embryonic anastomotic arteries among the carotid and basilar circulatory systems. The occipital artery emerges from the internal carotid, it connects the later with the external carotid artery and its proximal portion is formed by a channel of proatlantal artery [1]. From the above, it is clear one proatlantal artery might rise from the external carotid and another from the internal carotid. The VA may be absent or hypoplastic if there is a persistent proatlantal artery. Thus, a proatlantal artery might remain due to abnormalities of VA development [1].

Below the $\mathrm{C} 1$ posterior arch is observed a radiculomuscular branch that is formed due to the entrance of the artery. This branch passes between the atlantoxial joint (forward) and C2 nerve (downward) and was present at all specimens (100\%). Moreover, it appears to give two branches; a dural branch that courses to the dura with the $\mathrm{C} 2$ nerve and a muscular branch. The origin of this radiculomuscular branch is observed on the entrance point of the VA to the C1 TF and no cadaver presented it lower from the TF (Table 3). Similar were also the findings in the angiography studies of Zhu et al. (2018) [62]. 
Another muscular branch is formed by the artery above the $\mathrm{C} 1$ posterior arch and ran posterosuperiorly and medially. Four cadavers presented this branch both in the left and the right side, respectively ( $28.6 \%$ on each side, Table 3 ). Distal to this branch, the posterior meningeal artery is formed by the VA posteromedially. This artery was originated 7-11 mm proximal to the entrance point of VA to dural and was detected on the left side in 4 (28.6\%) cadavers, on the right side in $6(42 \%)$ specimens and it was missed in 4 (Table 3). Although the meningeal branches of the VA are small, they may become swollen in a plenty of pathologic circumstances. Both anterior and posterior meningeal branches originate from the extracranial VA and supply a portion of the dura of the posterior fossa. The posterior branch emerges from the VA over the arch of $\mathrm{C} 1$, under the foramen magnum and it supplies the medial portions of the dura of the occipital posterior fossa and the falx cerebelli. Sometimes it may also continue over the tentorium in order to supply the posterior segment of the falx cerebri and adjacent tentorium [37]. Newton (1968) [37] reported the posterior meningeal artery on the left side in $29.8 \%$ of their cases and on the right side in $40 \%$ of the cases (angiographic study). According to their study, the posterior meningeal artery originates from the posterior part of the VA among the arch of C1 and the base of the skull.

The posterior spinal artery arose from the posteromedial portion of the VA just at the point of entrance of the dural. It was observed on the left side in $4(28.6 \%)$ cadavers and on the right in $5(35.7 \%$, Table 3). It also can be emerged from the intradural segment of the artery $[11,23]$. In the subarachnoid space, the artery gives off ascendants and descendants branches. The ascendant branch passes through the foramen magnum and divides into branches that are connected to branches of the PICA. The descendant branch course continues on the posterolateral aspect of the spinal cord. It is also connected to the posterior branches of the radicular arteries and is divided into collateral branches, which continue medially across the posterior surface of the spinal cord and they are connected to form an artery located in the midline, parallel to the posterior spinal arteries. Concerning the dural penetration of the VA, the - partial - ligation of the artery at this level is recommend, because the periosteal sheath supports the dura mater. So, in rotations, is more secure to leave untouched the central part of the dura matter and cutting it around, but not close to the VA. The muscular branch above the posterior arch of $\mathrm{C} 1$ is commonly injured during exposure of the artery. Last but not least, the importance of distinguishing the VA from the PICA must be highlighted, as in rare occasions may emerges from the extradural VA [57].

\section{CONCLUSIONS}

It is obvious that, although the variations of VA concerning the origin, the course and the branches are, according to the literature, in most cases asymptomatic, the thorough comprehension and knowledge of the typical VA and its variations is of great importance for the prevention of vascular complications during minimally invasive diagnosis and treatment of cerebral vascular diseases.

\section{REFERENCES}

1. Abd el-Bary TH, Dujovny M, Ausman Jl. Microsurgical anatomy of the atlantal part of the vertebral artery. Surg Neurol. 1995; 44(4): 392-400; discussion 400, doi: 10.1016/0090-3019(95)00033-x, indexed in Pubmed: 8553261.

2. Adachi B. Das Arterien system der Japaner. Vol. 1. Verlag der Kaiserlich-Japanischen Universitat, Kenyusha Press, Kyoto 1928.

3. Afsharpour S, Hoiriis KT, Fox RB, et al. An anatomical study of arcuate foramen and its clinical implications: a case report. Chiropr Man Therap. 2016; 24: 4, doi: 10.1186/ s12998-016-0082-2, indexed in Pubmed: 26811743.

4. Ahn J, Duran M, Syldort S, et al. Arcuate foramen: anatomy, embryology, nomenclature, pathology, and surgical considerations. World Neurosurg. 2018; 118: 197-202, doi: 10.1016/j.wneu.2018.07.038, indexed in Pubmed: 30026164.

5. Bhatia K, Ghabriel MN, Henneberg M. Anatomical variations in the branches of the human aortic arch: a recent study of a South Australian population. Folia Morphol. 2005; 64(3): 217-223, indexed in Pubmed: 16228958.

6. Bhimabhai MP. A study of the branching pattern of aortic arch. Nat J Integr Res Med. 2014; 5: 27-30.

7. Bruneau M, Cornelius JF, Marneffe V, et al. Anatomical variations of the $\mathrm{V} 2$ segment of the vertebral artery. Neurosurgery. 2006; 59(1 Suppl 1): ONS20-4; discussion ONS20, doi: 10.1227/01.NEU.0000219931.64378.B5, indexed in Pubmed: 16888547.

8. Budhiraja V, Rastogi R, Jain V, et al. Anatomical variations in the branching pattern of human aortic arch: a cadaveric study from central India. ISRN Anat. 2013; 2013: 828969, doi: 10.5402/2013/828969, indexed in Pubmed: 25938106.

9. Cacciola F, Phalke U, Goel A. Vertebral artery in relationship to C1-C2 vertebrae: an anatomical study. Neurol India. 2004; 52(2): 178-184, indexed in Pubmed: 15269464.

10. Caplan LR. ertebrobasilar system syndromes. In: Vinken PJ, Bruyn GW, Klawans, eds. Handbook of clinical neurology. 
ascular disease. Part 1. Elsevier Science Publisher B.V., Amsterdam 1988: 371-409.

11. Carpenter MB. Neuroanatomy. 4th ed. Williams and Wilkins, Philadelphia 1991: 449.

12. Chanapa $P$, Mahakkanukrauh P. Anatomical variations of the V2 vertebral artery study by measuring the width of transverse foramen. J Med Assoc Thai. 2012; 95(4): 569-573, indexed in Pubmed: 22612013.

13. Civelek E, Kiris T, Hepgul K, et al. Anterolateral approach to the cervical spine: major anatomical structures and landmarks. Technical note. J Neurosurg Spine. 2007; 7(6): 669-678, doi: 10.3171/SPI-07/12/669, indexed in Pubmed: 18074695.

14. Cushing KE, Ramesh V, Gardner-Medwin D, et al. Tethering of the vertebral artery in the congenital arcuate foramen of the atlas vertebra: a possible cause of vertebral artery dissection in children. Dev Med Child Neurol. 2001; 43(7): 491-496, doi: 10.1017/s0012162201000901, indexed in Pubmed: 11463182.

15. De Oliveira E, Rhoton A, Peace D. Microsurgical anatomy of the region of the foramen magnum. Surg Neurol. 1985; 24(3): 293-352, doi: 10.1016/0090-3019(85)90042-4.

16. Ebraheim NA, Lu J, Brown JA, et al. Vulnerability of vertebral artery in anterolateral decompression for cervical spondylosis. Clin Orthop Relat Res. 1996(322): 146-151, indexed in Pubmed: 8542690.

17. Einstein EH, Song LH, Villela NLA, et al. Anomalous origin of the left vertebral artery from the aortic arch. Aorta (Stamford). 2016; 4(2): 64-67, doi: 10.12945/j. aorta.2015.15.022, indexed in Pubmed: 27757404.

18. Francke JP, di Mario V, Pannier M, et al. The vertebral arteries (arteriavertebralis). The V3 atlantoaxial and V4 intracranial segments-collaterals. Anat Clin (Berl). 1981; 2: 229-242.

19. Gluncic V, Ivkic $G$, Marin $D$, et al. Anomalous origin of both vertebral arteries. Clin Anat. 1999; 12(4): 281-284, doi: 10.1002/(SICI)1098-2353(1999)12:4<281::AID-CA8>3.0. CO;2-6, indexed in Pubmed: 10398389.

20. Haynes MJ, Cala LA, Melsom A, et al. Posterior ponticles and rotational stenosis of vertebral arteries. A pilot study using Doppler ultrasound velocimetry and magnetic resonance angiography. J Manipulative Physiol Ther. 2005; 28(5): 323-329, doi: 10.1016/j.jmpt.2005.04.003, indexed in Pubmed: 15965406.

21. Hecker P. Appareil ligamenteux occipito-atloïdo-axoïdien etude d'anatomie comparée: Archives d'Anatomie, D'Histologie et d'Embryologie. 1922; 1: 417-433.

22. Heros RC. Lateral suboccipital approach for vertebral and vertebrobasilar artery lesions. J Neurosurg. 1986; 64(4): 559-562, doi: 10.3171/jns.1986.64.4.0559, indexed in Pubmed: 3950739.

23. Hong JT, Park DK, Lee MJ, et al. Anatomical variations of the vertebral artery segment in the lower cervical spine: analysis by three-dimensional computed tomography angiography. Spine. 2008; 33(22): 2422-2426, doi: 10.1097/ BRS.0b013e31818938d1, indexed in Pubmed: 18923317.

24. Ikegami A, Ohtani Y, Ohtani O. Bilateral variations of the vertebral arteries: the left originating from the aortic arch and the left and right entering the $\mathrm{C} 5$ transverse foramina. Anat Sci Int. 2007; 82(3): 175-179, doi: 10.1111/j.1447073X.2006.00163.x, indexed in Pubmed: 17867344.
25. Kendi AT, Brace JR. Vertebral artery duplication and aneurysms: 64-slice multidetector CT findings. Br J Radiol. 2009; 82(983): e216-e218, doi: 10.1259/bjr/26005109, indexed in Pubmed: 19890113.

26. Krayenbühl H, Yasargil MG. Die vaskulären Erkankungen im Gebiet der Arteria vertebralis. Eine anatomische und pagänzungband der Fortschritte auf dem Gebiete der Röntgenstrahlen und der Nuklearmedizin. Thieme, Stuttgart 1957.

27. Lang J, Kessler B. About the suboccipital part of the vertebral artery and the neighboring bone-joint and nerve relationships. Skull Base Surg. 1991; 1(1): 64-72, doi: 10.1055/s-2008-1056982, indexed in Pubmed: 17170824.

28. Lang J. Clinical anatomy of the head: neurocranium, orbit and craniocervical regions. Springer-Verlag, New York 1983.

29. Lazaridis N, Piagkou M, Loukas M, et al. A systematic classification of the vertebral artery variable origin: clinical and surgical implications. Surg Radiol Anat. 2018; 40(7): 779-797, doi: 10.1007/s00276-018-1987-3, indexed in Pubmed: 29459992.

30. Li X, Guan L, Zilundu PLM, et al. The applied anatomy and clinical significance of the proximal, $\mathrm{V} 1$ segment of vertebral artery. Folia Morphol. 2019; 78(4): 710-719, doi: 10.5603/FM.a2019.0039, indexed in Pubmed: 30949997.

31. Maiti TK, Konar SK, Bir S, et al. Anomalous origin of the right vertebral artery: incidence and significance. World Neurosurg. 2016; 89: 601-610, doi: 10.1016/j. wneu.2015.11.018, indexed in Pubmed: 26897702.

32. Manjunath KY. Posterior bridging of the atlas vertebra in south Indians. Indian J Med Sci. 2001; 55(9): 488-490, indexed in Pubmed: 11887298.

33. Mitchell $J$. The incidence of the lateral bridge of the atlas vertebra. J Anat. 1998; 193 (Pt 2): 283-285, doi: 10.1046/j.1469-7580.1998.19320283.x, indexed in Pubmed: 9827643.

34. Momma K, Matsuoka R, Takao A. Aortic arch anomalies associated with chromosome 22q11 deletion (CATCH 22). Pediatr Cardiol. 1999; 20(2): 97-102, doi: 10.1007/ s002469900414, indexed in Pubmed: 9986884.

35. Motomura M, Watanabe K, Tabira Y, et al. A case of duplicated right vertebral artery. Kurume Med J. 2018; 64(3): 69-73, doi: 10.2739/kurumemedj.MS643004, indexed in Pubmed: 29553097.

36. Muralimohan S, Pande A, Vasudevan MC, et al. Suboccipital segment of the vertebral artery: a cadaveric study. Neurol India. 2009; 57(4): 447-452, doi: 10.4103/00283886.55610, indexed in Pubmed: 19770546.

37. Newton TH. The anterior and posterior meningeal branches of the vertebral artery. Radiology. 1968; 91(2): 271-279, doi: 10.1148/91.2.271, indexed in Pubmed: 4298412.

38. Ohkura K, Shiiya N, Washiyama N, et al. Vertebral artery variations in thoracic aortic patients. Eur J Cardiothorac Surg. 2014; 46(1): 27-31, doi: 10.1093/ejcts/ezt609, indexed in Pubmed: 24446475.

39. O'Malley AM, El Kininy WH, Debebe H, et al. A cadaveric study of aortic arch variation in an Irish population. Ir J Med Sci. 2018; 187(3): 853-858, doi: 10.1007/s11845017-1729-2, indexed in Pubmed: 29288397.

40. Paraskevas G, Papaziogas B, Tsonidis C, et al. Gross morphology of the bridges over the vertebral artery groove on the 
atlas. Surg Radiol Anat. 2005; 27(2): 129-136, doi: 10.1007/ s00276-004-0300-9, indexed in Pubmed: 15800734.

41. Patil ST, Meshram MM, Kamdi NY, et al. Study on branching pattern of aortic arch in Indian. Anat Cell Biol. 2012; 45(3): 203-206, doi: 10.5115/acb.2012.45.3.203, indexed in Pubmed: 23094209.

42. Pękala PA, Henry BM, Pękala JR, et al. Prevalence of foramen arcuale and its clinical significance: a meta-analysis of 55,985 subjects. J Neurosurg Spine. 2017; 27(3): 276-290, doi: 10.3171/2017.1.SPINE161092, indexed in Pubmed: 28621616.

43. Pick TP, Howden R. Gray's anatomy, descriptive and surgical. Bounty Books, New York 1901.

44. Russo VM, Graziano F, Peris-Celda M, et al. The V(2) segment of the vertebral artery: anatomical considerations and surgical implications. J Neurosurg Spine. 2011; 15(6): 610-619, doi: 10.3171/2011.7.SPINE1132, indexed in Pubmed: 21905775.

45. Schwedt K. Form-und Lagervariationen der extrakraniellen Arteria vertebralis im Angiogramm. Medical Dissertation, Wurzburg 1978.

46. Senoglu M, Gümüşalan Y, Yüksel KZ, et al. The effect of posterior bridging of $\mathrm{C}-1$ on craniovertebral junction surgery. J Neurosurg Spine. 2006; 5(1): 50-52, doi: 10.3171/ spi.2006.5.1.50, indexed in Pubmed: 16850956.

47. Shin IY, Chung YG, Shin WH, et al. A morphometric study on cadaveric aortic arch and its major branches in 25 Korean adults: the perspective of endovascular surgery. J Korean Neurosurg Soc. 2008; 44(2): 78-83, doi: 10.3340/ jkns.2008.44.2.78, indexed in Pubmed: 19096697.

48. Sim E, Vaccaro AR, Berzlanovich A, et al. Fenestration of the extracranial vertebral artery: review of theliterature. Spine. 2001; 26: E139-E142.

49. Singh R. Two rare variants of left vertebral artery. J Craniofac Surg. 2017; 28(4): 1105-1106, doi: 10.1097/ SCS.0000000000003515, indexed in Pubmed: 28207465.

50. Taitz C, Nathan H. Some observations on the posterior and lateral bridge of the atlas. Acta Anat (Basel). 1986; 127(3): 212-217, doi: 10.1159/000146284, indexed in Pubmed: 3788469.

51. Tardieu GG, Edwards B, Alonso F, et al. Aortic arch origin of the left vertebral artery: an anatomical and radiological study with significance for avoiding complications with anterior approaches to the cervical spine. Clin Anat. 2017; 30(6): 811-816, doi: 10.1002/ca.22923, indexed in Pubmed: 28547783.

52. Toldt C, Hochstetter F. Anatomischer Atlas, vol. 2, 27th ed. Urban \& Schwarzenberg, München 1979.
53. Tubbs RS, Stetler W, Shoja MM, et al. The lateral atlantooccipital ligament. Surg Radiol Anat. 2007; 29(3): 219-223, doi: 10.1007/s00276-007-0196-2, indexed in Pubmed: 17342571.

54. Ulm AJ, Quiroga M, Russo A, et al. Normal anatomical variations of the $V_{3}$ segment of the vertebral artery: surgical implications. J Neurosurg Spine. 2010; 13(4): 451-460, doi: 10.3171/2010.4.SPINE09824, indexed in Pubmed: 20887142.

55. Vanitha V, Teli CG, Kadlimatti HS. Bilateral posterior and lateral ponticles resulting in the formation of vertebral artery canal for the atlas: case report. IOSR J Dental Med Sci. 2014; 13(5): 82-84, doi: 10.9790/0853-13548284.

56. Vorster W, du Plooy PT, Meiring JH. Abnormal origin of internal thoracic and vertebral arteries. Clin Anat. 1998; 11(1): 33-37, doi: 10.1002/(sici)10982353(1998)11:1<33::aid-ca5>3.0.co;2-t.

57. Wakao N, Takeuchi M, Nishimura M, et al. Vertebral artery variations and osseous anomaly at the C1-2 level diagnosed by 3D CT angiography in normal subjects. Neuroradiology. 2014; 56(10): 843-849, doi: 10.1007/ s00234-014-1399-y, indexed in Pubmed: 25001076.

58. Wang X, Tang G, Li M. Bilateral extradural posterior inferior cerebellar artery origins where vertebral artery ascends between transverse foramina of C-2 and C-1, with simultaneous right double origin PICA: rare case report and literature review. World Neurosurg. 2019; 125 : 234-239, doi: 10.1016/j.wneu.2019.01.233, indexed in Pubmed: 30771546.

59. Wight S, Osborne N, Breen AC. Incidence of ponticulus posterior of the atlas in migraine and cervicogenic headache. J Manipulative Physiol Ther. 1999; 22(1): 15-20, doi: 10.1016/ s0161-4754(99)70100-4, indexed in Pubmed: 10029944.

60. Woraputtaporn W, Ananteerakul T, lamsaard S, et al. Incidence of vertebral artery of aortic arch origin, its level of entry into transverse foramen, length, diameter and clinical significance. Anat Sci Int. 2019; 94(4): 275-279, doi: 10.1007/ s12565-019-00482-6, indexed in Pubmed: 30806941.

61. Yamaki Ki, Saga T, Hirata T, et al. Anatomical study of the vertebral artery in Japanese adults. Anat Sci Int. 2006; 81(2): 100-106, doi: 10.1111/j.1447-073x.2006.00133.x, indexed in Pubmed: 16800294.

62. Zhu SW, Yang Y, Liu YG, et al. Anatomical features and clinical significance of radiculomuscular artery variants involving the suboccipital segment of vertebral artery: angiographic and cadaver studies. Clin Neuroradiol. 2018; 28(1): 75-80, doi: 10.1007/s00062-016-0520-5, indexed in Pubmed: 27325366. 